\title{
Foveolar type dysplasia in Barrett esophagus
}

\author{
Ian S Brown ${ }^{1}$, David C Whiteman ${ }^{2,3}$ and Gregory Y Lauwers ${ }^{4}$ \\ ${ }^{1}$ Sullivan Nicolaides Pathology and Royal Brisbane and Women's Hospital Brisbane, Brisbane, Australia; \\ ${ }^{2}$ Division of Population Studies and Human Genetics, Queensland Institute of Medical Research, \\ Queensland, Australia; ${ }^{3}$ Division of Cancer and Cell Biology, Queensland Institute of Medical Research, \\ Queensland, Australia and ${ }^{4}$ Massachusetts General Hospital, Boston, MA, USA
}

\begin{abstract}
Adenocarcinoma of the lower esophagus and esophagogastric junction is increasing in incidence in Western countries. A metaplasia (Barrett esophagus)-dysplasia-carcinoma sequence induced by gastroesophageal reflux disease is established. Two patterns of Barrett dysplasias have been described-adenomatous (type 1) and non-adenomatous (type 2 or foveolar/hyperplastic type). Interestingly, little is known about non-adenomatous dysplasia. Esophagogastrectomy cases from 41 patients with glandular dysplasia with and without associated invasive adenocarcinoma of the lower esophagus were evaluated for expression of MUC2, MUC5AC, CDX2, villin, Ki67 and p53. Results were correlated with sub-classification of the dysplasia into morphologic patterns of adenomatous vs foveolar vs hybrid type. In addition, clinicopathological parameters including the presence and extent of background intestinal metaplasia were also evaluated. Foveolar type dysplasia was present in $46 \%$ of the cases and thus, was more common than adenomatous type or hybrid type (both $\sim 27 \%$ ) dysplasia. Immunohistochemistry confirmed the histological stratification in all cases. Foveolar type dysplasia commonly expressed MUC5AC $(P<0.12)$ but was consistently negative for markers of intestinal differentiation, MUC2, CDX2 and villin (all $P<0.01$ ). By contrast, adenomatous type dysplasia frequently displayed intestinal differentiation markers (all $\boldsymbol{P}<0.0001$ ) Hybrid-type dysplasia was similar to adenomatous type dysplasia in showing expression of intestinal differentiation markers $(P<0.01)$ and therefore could not be sustained as a separate category. In conclusion, our study provides evidence for a non intestinal pathway to neoplastic development in Barrett esophagus, that is, gastric metaplasia-foveolar dysplasia-adenocarcinoma.
\end{abstract}

Modern Pathology (2010) 23, 834-843; doi:10.1038/modpathol.2010.59; published online 12 March 2010

Keywords: foveolar dysplasia; Barrett esophagus; intestinal metaplasia

Barrett esophagus, also termed columnar lined esophagus, is a metaplastic condition in which the normal non-keratinizing squamous epithelium of the esophagus is replaced by a columnar mucosa. Barrett esophagus is a consequence of gastroesophageal reflux disease and is significant in being at risk for neoplastic transformation through a metaplasia-dysplasia-carcinoma sequence. In Western populations, there has been a dramatic rise in the incidence of adenocarcinoma of the esophagus and esophago-gastric junction region ${ }^{1-4}$ that parallels an increase in the prevalence of Barrett esophagus. ${ }^{5}$

Although, three epithelial types, gastric cardiac, gastric fundic and intestinal type ${ }^{6}$ are recognized to

Correspondence: Dr IS Brown, Department of Histopathology, Sullivan Nicolaides Pathology, 134 Whitmore street Taringa, Queensland 4068, Australia.

E-mail: ian_brown@snp.com.au

Received 25 November 2009; revised 27 January 2010; accepted 28 January 2010; published online 12 March 2010 constitute Barrett esophagus, a number of studies have concluded that the intestinal type characterized by intestinal metaplasia is the most important antecedent to dysplasia development in Barrett esophagus. ${ }^{7-9}$ However, it is recognized that intestinal metaplasia is not always identified adjacent to invasive adenocarcinoma of the lower esophagus or gastroesophageal junction region. ${ }^{10-17}$ Nevertheless, it has been reported that the Barrett esophagus columnar mucosa is 'intestinalized' when examined by immunohistochemical markers of intestinal differentiation, even in the absence of histological evidence of intestinal metaplasia, that is, goblet cells. $^{18-23}$ Thus supporting the current American College of Gastroenterology guidelines, which require the presence of intestinal metaplasia for the diagnosis of Barrett esophagus. ${ }^{24}$

Clinical experience has suggested the presence of two cyto-architectural patterns of Barrett esophagus dysplasia and the terms type 1 and type 2 or adenomatous and non adenomatous (also known 
as 'foveolar/hyperplastic') akin to gastric dysplasia, have been applied to these patterns. ${ }^{16,25-28}$ The adenomatous pattern of dysplasia is said to account for the majority of cases and resembles colorectal adenoma. ${ }^{16}$ By contrast, non adenomatous dysplasia is reported to be uncommon. Rounded cells with vesicular nuclei and prominent nucleoli are the usual cytological features, whereas closely packed glands constitute the main architectural characteristic. $^{26}$ Notably, in a recent study of endoscopic biopsies, ${ }^{18}$ Barrett esophagus patients with a non adenomatous pattern of dysplasia showed no significant differences regarding either flow cytometric abnormalities or progression to cancer compared with adenomatous dysplasia ${ }^{29}$

Recent advances in mucin and other immunohistochemistry have enabled better characterization of premalignant conditions of the stomach and pancreas, and in both conditions, this subdivision has clinicopathological relevance. ${ }^{27,30-32}$ To date, no formal analysis of a possible similar division has been undertaken in the setting of Barrett esophagusrelated dysplasia. However, as the gastric and intestinal epithelium of Barrett esophagus is in essence the same background that gastric dysplasia arises, it seems reasonable to assume a similar classification scheme to Barrett esophagus dysplasia may apply. This study investigates a morphological sub-classification of Barrett dysplasia and the clinicopathological characteristics of such a classification.

\section{Materials and methods}

\section{Clinical Characteristics}

We reviewed the histological sections from a consecutive series of eighty-one (81) esophagogastrectomy cases received and reported at Sullivan Nicolaides Pathology between June 2001 and December 2006 and entered into the Australian Cancer Study for Esophageal Carcinoma. ${ }^{33}$ Eight (8) cases of esophageal squamous cell carcinoma were excluded, leaving seventy-three (73) cases (invasive adenocarcinoma $n=68$, high-grade dysplasia $n=5$ ).

After formalin fixation, the specimens were dissected in the following manner. Tumors $\leq 30 \mathrm{~mm}$ in diameter (enabling a complete section to fit in a standard tissue cassette) were entirely embedded along with the entire gastro-esophageal junction and any abnormal mucosa (that is, Barrett esophagus) that accompanied the tumor. Tumors $>30 \mathrm{~mm}$ in diameter were sampled by at least three sections of tumor and at least one of the tumor to normal esophagus interface. For cases with a biopsy diagnosis of high-grade dysplasia, the entire abnormal area including gastro-esophageal junction, was embedded. Using this dissection approach, an average of eight tumor (with or without Barrett esophagus) sections were taken per case. The tissue blocks were routinely fixed in 10\% buffered formalin, embedded in paraffin, cut at $5 \mu \mathrm{m}$ and then stained with hematoxylin and eosin. The location of the invasive adenocarcinoma, when present, was recorded with respect to the WHO guidelines. ${ }^{34}$ Briefly, tumors spanning the gastro-esophageal junction were called adenocarcinomas of the gastro-esophageal junction regardless of the epicenter of the bulk of the tumor. Tumors located entirely above the gastro-esophageal junction were defined as esophageal adenocarcinomas, whereas adenocarcinomas located entirely below the gastroesophageal junction were considered gastric adenocarcinomas. The macroscopic tumor size was recorded.

\section{Classification of Glandular Dysplasia and Assessment of the Background Mucosa}

Unequivocal glandular dysplasia was classified as either adenomatous (intestinal) type, gastric foveolar type or hybrid type according to morphological features previously documented ${ }^{16,28}$ and expanded upon as follows. Adenomatous-type dysplasia resembles colorectal adenoma by being composed of glands or villous structures lined by tall columnar cells with hyperchromatic, pencillate, variably stratified nuclei and dense eosinophilic cytoplasm (Figure 1). Gland luminal borders have a sharp edge and goblet cells and Paneth cells are often identified. Foveolar type dysplasia is characterized by cuboidal to columnar cells with pale clear to light eosinophilic cytoplasm and round to oval nuclei, some of which have discernable small nucleoli (Figure 2). The glands have a propensity to be smaller and more closely associated than adenomatous dysplasia and the luminal borders are less distinct. Goblet cells and Paneth cells are absent in foveolar dysplastic epithelium. Hybrid dysplasia shows cytological features intermediate between these two patterns or an intimate admixture of both adenomatous and foveolar cell types. We would also consider the finding of intermixed 'clone-like' foci of foveolar type and adenomatous type dysplasia together within a dysplastic area as representing hybrid dysplasia, although we did not observe this in our cases. The grade of dysplasia was assessed as low or high-grade dysplasia on the basis of standardized criteria previously published ${ }^{35}$ Only recently have been proposed specific grading criteria for foveolar type dysplasia, although their reproducibility have not been tested. ${ }^{36}$ All sections of the background non-dysplastic columnar mucosa were assessed with respect to the presence of goblet cells and the density of goblet cells per gland. Goblet cell density was determined in up to one low power field $(\times 20$, field diameter $10 \mathrm{~mm})$ immediately adjacent to dysplasia. This often contained all metaplastic but non dysplastic epithelium available for assessment in the sections taken. Where present 

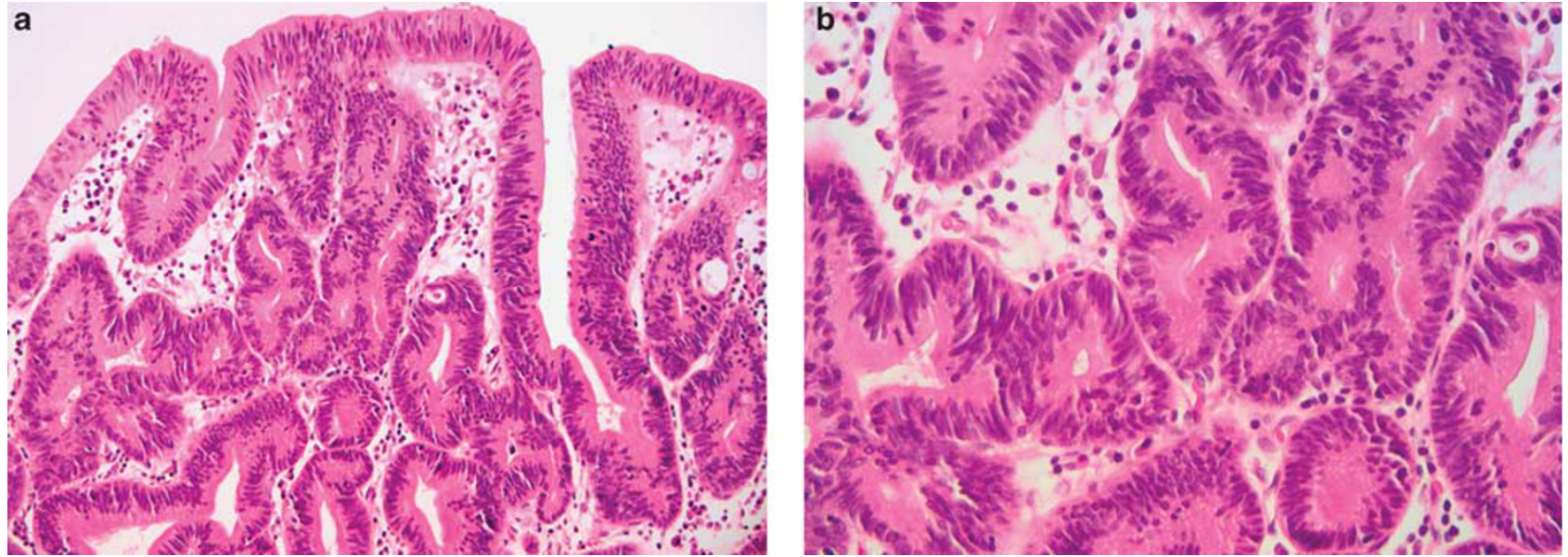

Figure 1 Histological features of adenomatous-type dysplasia (a) Low power view of adenomatous dysplasia displaying tubular architecture and cells with eosinophilic cytoplasm. (b) High power view of adenomatous dysplasia displaying eosinophilic cytoplasm with sharp luminal borders and stratified pencillate nuclei.
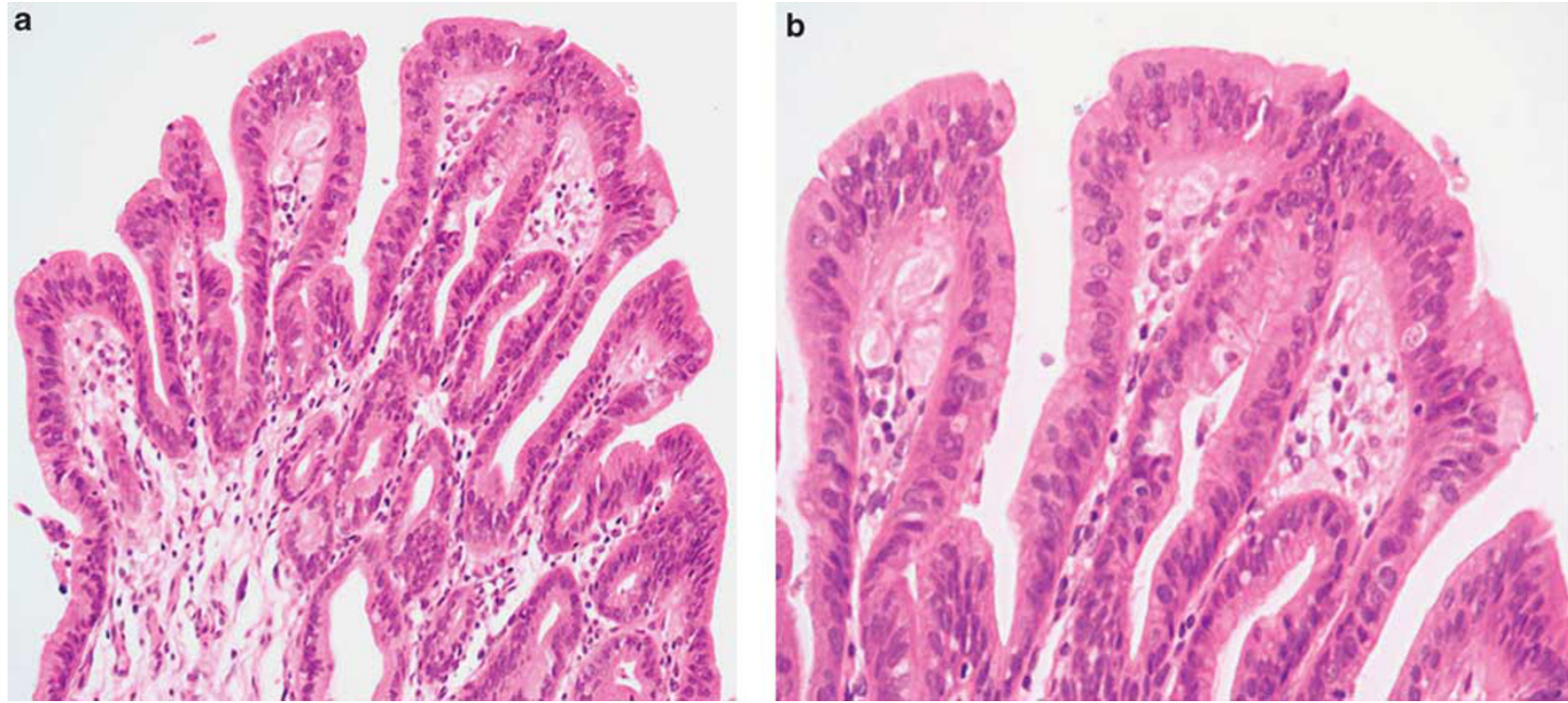

Figure 2 Histological features of foveolar type dysplasia (a) Medium power view of foveolar type dysplasia showing villiform architecture, tall columnar cells with abundant pale staining cytoplasm and basal nuclei. (b) High power view of foveolar dysplasia showing round to oval basal nuclei some of which have discernable nucleoli.

the density of goblet cells per gland was assessed as low density ( $\leq 5$ goblet cells per gland) or high density ( $>5$ goblet cells per gland). As the study cases were orientated resection specimens (as opposed to biopsy cases), a gland spanned the full thickness of the mucosa. The identification of goblet cells was based on histological appearance and positive immunostain reaction for MUC2. Finally, as the major aim of this study was to investigate patterns of glandular epithelial dysplasia arising in Barrett metaplastic epithelium, objective evidence for an esophageal origin was sought. In keeping with previous reports, ${ }^{37-40}$ the presence of double muscularis mucosae, esophageal gland ducts and/or oesophageal submucosal glands lying im- mediately subjacent to the area of dysplasia were considered objective measures for an oesophageal location.

\section{Immunohistochemical Evaluation}

Each case in which dysplasia was identified was evaluated by the following immunohistochemical stains: p53 (D0-7, 1:50; Dako), Ki67 (30-9, predilute; Ventana), MUC2 (Ccp58, 1:100; Novocastra laboratories), MUC5AC (CLH2, 1:100; Novocastra laboratories), CDX2 (AMT28, 1:50; Novocastra laboratories) and villin (CWWB1, 1:50; Novocastra laboratories). 
MUC2, CDX2 and villin served as markers of intestinal differentiation. As these three immunohistochemical reagents target different aspects of cellular intestinal differentiation (for example, MUC2-intestinal mucin, CDX2-intestinal homeobox gene, villin-associated with microvillus structure) we felt this combination gave the most sensitive method to detect intestinal expression. MUC5AC is a specific gastric foveolar mucin and served as a marker of foveolar differentiation.

Briefly, the immunohistochemical technique was as follows. Five-micron thick consecutive sections were deparaffinized and hydrated through a graded series of alcohol. Following antigen retrieval with $10 \mathrm{ml}$ per liter of citrate buffer $(\mathrm{pH}$ 6.0) in a microwave oven for $10 \mathrm{~min}$, the addition of endogenous peroxidase activity by immersion into $3 \%$ $\mathrm{H}_{2} \mathrm{O}_{2}$ /methanol solution was performed. The sections were then incubated with the primary antibodies followed by washing in phosphate-buffered solution, incubation with biotinylated secondary antibody and then with avidin-biotinylated horse radish peroxidase complex and finely developed using 3, 3, -Diaminobenzidine Tetrachloride as the chromagen. Nucleus counter staining was accomplished with hematoxylin. P53 staining was regarded as positive only when strong nuclear staining was seen. Reaction for MUC2 and MUC5AC, was considered positive when $\geq 10 \%$ of dysplastic cells were immuno-reactive and negative when the extent of staining was $<10 \%$. Staining for CDX-2 was considered positive when $\geq 10 \%$ of cells displayed nuclear positivity. Staining for villin was considered positive when $\geq 10 \%$ of cells displayed cell membrane reaction.

\section{Statistical Analysis}

The statistical analysis was performed by a biostatistician using $\chi^{2}$-test for differences between the groups. A $P<0.05$ was considered statistically significant.

\section{Results}

\section{Clinicopathological Characteristics of The Study Group}

The study group comprised 73 cases (invasive adenocarcinoma $n=68$, high-grade dysplasia $n=5$ ). Consistent with previous observations, males $(n=67,92 \%)$ vastly outnumbered female patients $(n=6,8 \%)$. The mean age of the patients was 64 years (s.d. \pm 10.4 years). In 57 cases the invasive adenocarcinoma was grossly identified as crossing the esophago-gastric junction. It was confined to the lower esophagus in nine cases and was localized entirely in the gastric cardia (proximal stomach) in two cases. Eleven patients had a history of preoperative radiotherapy. Of these, nine patients showed extensive tumor regression and had no dysplasia evident. In the remaining two cases there was minimal tumor regression and residual dysplasia was present (one adenomatous type and one foveolar type).

The mean size of the tumors was $32 \mathrm{~mm}$ (range: $3-80 \mathrm{~mm}$ in diameter). Barrett esophagus with dysplasia was identified in 41 cases $(56 \%)$ (the eventual study population) and ranged in extent from 0.5 to $55 \mathrm{~mm}$ in the tissue sections (average $14 \mathrm{~mm}$, median $10 \mathrm{~mm}$ ).

The extent of Barrett esophagus with dysplasia was most in the adenomatous dysplasia group (average $17 \mathrm{~mm}$, median $11 \mathrm{~mm}$ ) and least in the foveolar dysplasia group (average $9 \mathrm{~mm}$, median $7 \mathrm{~mm}$ ). No dysplastic epithelium was identified adjacent to the two gastric cardia tumors.

Lesional tissue, consisting of Barrett esophagus, Barrett esophagus with dysplasia and invasive adenocarcinoma (if present), was fully embedded in 28 of the $41(68 \%)$ specimens in which dysplasia was identified. An average of six blocks of lesional tissue (range: 4-7) was examined in the other 13 cases.

Morphologically, 11 of the 41 cases of dysplasia were of the adenomatous and hybrid types $(27 \%$ each) whereas 19 cases were of the foveolar type $(46 \%)$. Confirming the esophageal location, either a double-layered muscularis mucosae $(n=26)$ or esophageal submucosal glands and/or gland ducts $(n=21)$ were identified subjacent to dysplasia in $83 \%$ of the cases $(n=34)$. Of the seven remaining cases $(17 \%)$, three had previous macroscopic and endoscopic evidence of Barrett esophagus. In the remaining four cases, the associated invasive tumors were large $(35-60 \mathrm{~mm}$ diameter), straddled the gastro-esophageal junction and dysplasia was identified in sections proximal (esophageal) to the tumor. Goblet cells were not identified in glandular mucosa adjacent to dysplasia in 4 of the 28 fully sectioned cases $(14 \%)$. In these, the extent of glandular epithelium ranged from 2 to $6 \mathrm{~mm}$.

\section{Clinicopathological Comparison of the three Types of Dysplasia}

The three types of dysplasia did not significantly differ with regard to the patient's average age or the size of the associated invasive adenocarcinoma. Only two female patients were diagnosed with dysplasia and in both cases this was of foveolar type (Table 1).

A tubular architectural pattern was commonly seen in all three dysplastic types. Adenomatous type dysplasia was the least likely to show a villiform architecture (18\%).

High grade dysplasia was more commonly identified in the adenomatous and hybrid types (91 and $100 \%$, respectively) than in the foveolar type (58\%). 
Table 1 Clinicopathological features of morphological subtypes

\begin{tabular}{|c|c|c|c|}
\hline & Foveolar $(\mathrm{n}=19)$ & $\begin{array}{l}\text { Morphological subtype } \\
\text { Adenomatous }(\mathrm{n}=11)\end{array}$ & Hybrid $(\mathrm{n}=11)$ \\
\hline Age (years, mean \pm s.d.) & $63.7 \pm 12.2$ & $67.9 \pm 10.4$ & $65.6 \pm 10.4$ \\
\hline \multicolumn{4}{|l|}{ Sex } \\
\hline Males & $17(89 \%)$ & $11(100 \%)$ & $11(100 \%)$ \\
\hline Females & $2(11 \%)$ & 0 & 0 \\
\hline Invasive tumor size (mm, mean \pm s.d.) & $27.4 \pm 18.8$ & $27.4 \pm 18.1$ & $45.0 \pm 14.7$ \\
\hline Double muscularis & $8(42 \%)$ & $7(64 \%)$ & $5(45 \%)$ \\
\hline Submucosal glands & $14(74 \%)$ & $8(73 \%)$ & $3(27 \%)$ \\
\hline \multicolumn{4}{|l|}{ Architecture } \\
\hline Tubular pattern & $7(37 \%)$ & $5(45 \%)$ & $6(55 \%)$ \\
\hline Villiform pattern & $6(32 \%)$ & $2(18 \%)$ & $4(36 \%)$ \\
\hline Hybrid architecture & $6(32 \%)$ & $4(36 \%)$ & $1(9 \%)$ \\
\hline \multicolumn{4}{|l|}{ Dysplasia } \\
\hline Low-grade dysplasia & $16(84 \%)$ & $4(36 \%)$ & $6(55 \%)$ \\
\hline High-grade dysplasia & $11(58 \%)$ & $10(91 \%)$ & $11(100 \%)$ \\
\hline \multicolumn{4}{|l|}{ Goblet cells } \\
\hline Absent & $10(53 \%)$ & $1(9 \%)$ & $2(18 \%)$ \\
\hline Focal or intermediate goblet cells & $7(37 \%)$ & $2(18 \%)$ & $4(36 \%)$ \\
\hline Diffuse & $2(11 \%)$ & $7(64 \%)$ & $5(45 \%)$ \\
\hline Low-density & $4(21 \%)$ & $4(36 \%)$ & $4(36 \%)$ \\
\hline High-density & $5(26 \%)$ & $6(55 \%)$ & $5(45 \%)$ \\
\hline
\end{tabular}

Foveolar-type dysplasia was more likely to show no intestinal metaplasia in adjacent non dysplastic columnar mucosa compared with either adenomatous or hybrid-type dysplasia (47 vs 0 and $18 \%$, respectively, $P<0.0001$ ). In contrast, a diffuse goblet cell pattern was significantly more common in the background of adenomatous and hybrid-type dysplasia than foveolar type (64 and 45 vs $11 \%$, $P<0.0001)$.

\section{Immunohistochemical Stain Validation of the Three Morphological Subtypes}

Immunohistochemical reactions for MUC2, MUC5AC, CDX-2 and villin supported the morphological subclassification of dysplasia. Foveolar dysplasia cases were usually MUC5AC-positive (74\%, $P<0.12$ ) and did not show reaction for the three markers of intestinal differentiation, MUC2, CDX-2 and villin (all $P<0.01$; Figure 3 ) (Table 2). In contrast, adenomatous-type dysplasia displayed statistically significant immunoreaction for MUC 2, CDX-2 and villin (all $P<0.0001$; Figure 4). The hybrid type of dysplasia displayed reactivity closely resembling adenomatous-type dysplasia with statistically significant expression of intestinal markers $(P<0.01)$.

The immunohistochemical reaction pattern for intestinal markers strongly correlated with the presence and density of goblet cells in adjacent non neoplastic mucosa independent of the dysplasia pattern (MUC $2 \quad P<0.05$; CDX-2 $P<0.05$; villin $P<0.005)$. Not surprisingly, MUC5AC expression showed no correlation with goblet cell presence.
In all cases, there was an increased expression of Ki67 ( $>25 \%$ ) in dysplastic epithelium whereas non neoplastic epithelium showed negligible immunoreaction $(<1 \%)$. P53 expression was largely disappointing, a factor we attributed to the archival nature of the study material (there was similar low expression in the associated invasive tumors). Nonetheless, p53 expression was lower in the foveolar dysplasia subtype (11 vs $45-55 \%$ for adenomatous/hybrid types).

Comparative evaluation of the phenotype and immunophenotype of dysplasia and associated adenocarcinoma was not part of the scope of our study. However, we did notice a greater immunophenotypic variation in the associated invasive carcinoma than in dysplasia, and an apparent absence of correlation between dysplasia and adenocarcinoma.

\section{Discussion}

Although Barrett esophagus is a metaplastic condition comprising gastric and/or intestinal type columnar epithelium, the prevailing opinion held by many is that only the intestinal epithelium portends a neoplastic risk. This is reflected in the current American College of Gastroenterology guidelines for the diagnosis of Barrett esophagus, which require the presence of intestinal metaplasia to initiate screening. ${ }^{24}$ By extension, much emphasis has been placed on the adenomatous, that is, intestinal character of dysplasia in Barrett esophagus. However, at least some cases of Barrett esophagus dysplasia appear to have gastric foveolar cytomor- 
a
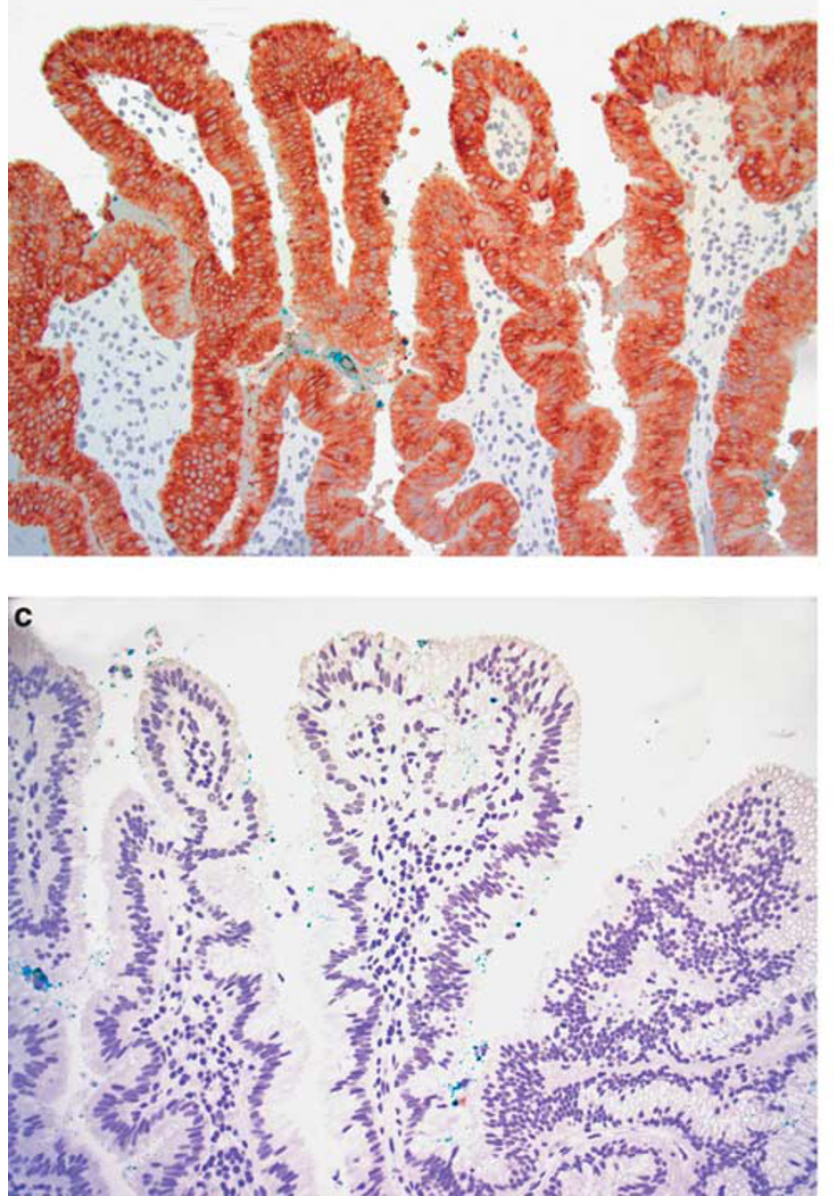

b
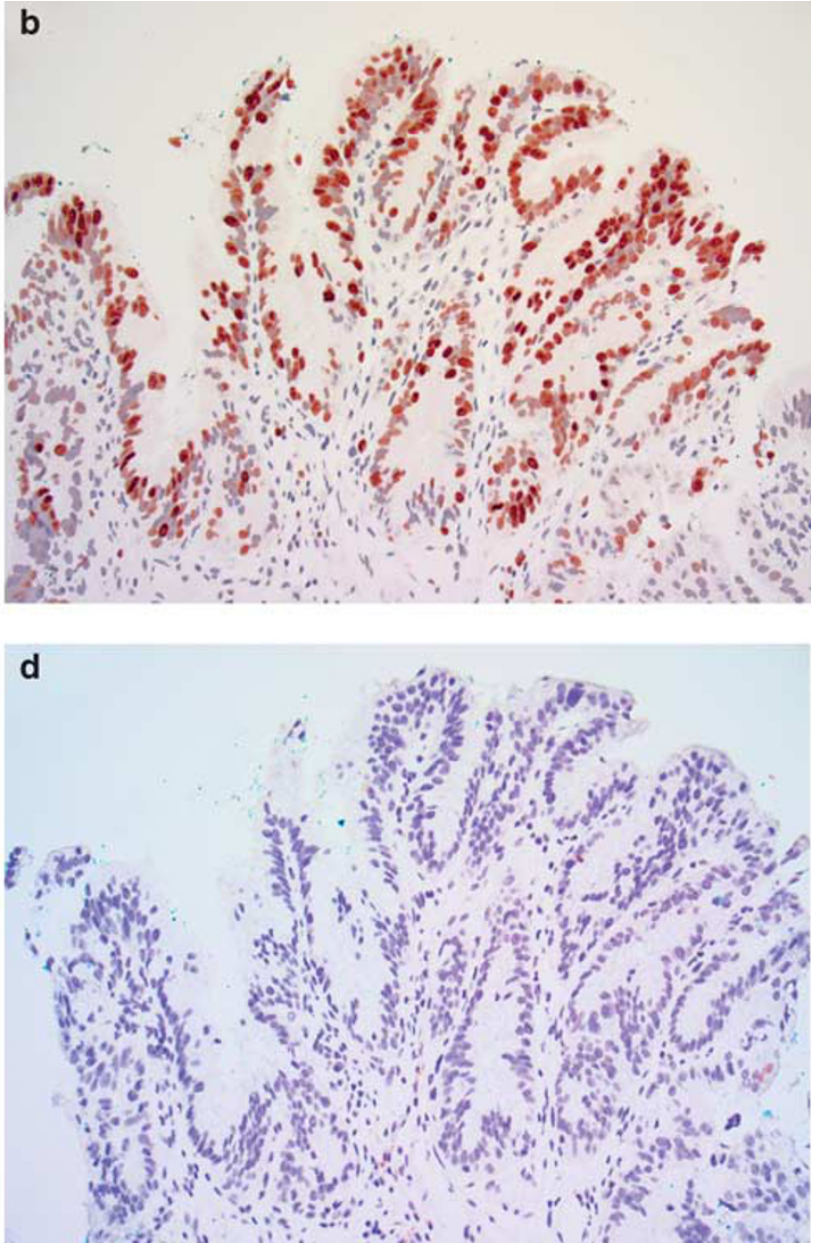

Figure 3 Foveolar-type dysplasia. (a) Tumor cells are strongly positive for MUC5AC. (b) High proliferation rate on Ki67 staining. (c) Negative for MUC2. (d) Negative for CDX2.

Table 2 Immunohistochemical profile of morphological subtypes

Morphological subtype

Foveolar $(\mathrm{n}=19)$

Adenomatous ( $\mathrm{n}=11$ )

Hybrid ( $\mathrm{n}=11)$
Immunophenotype
MUC 2
Negative $(<10 \%)$
Positive $(\geq 10 \%)$
MUC 5AC
Negative $(<10 \%)$
Positive $(\geq 10 \%)$
CDX-2
Negative $(<10 \%)$
Positive $(\geq 10 \%)$
Villin
Negative $(<10 \%)$
Positive $(\geq 10 \%)$
P53
Negative $(<10 \%)$
Positive $(\geq 10 \%)$

$19(100 \%)$
0
$14(74 \%)$
$5(26 \%)$
$19(100 \%)$
0
$19(100 \%)$
0
$17(89 \%)$
$2(11 \%)$

$4(36 \%)$
$7(64 \%)$
$5(45 \%)$
$6(55 \%)$
$2(18 \%)$
$9(82 \%)$
$2(18 \%)$
$9(82 \%)$
$5(45 \%)$
$6(55 \%)$

$8(73 \%)$

$3(27 \%)$

$5(45 \%)$

$6(55 \%)$

$4(36 \%)$

$7(64 \%)$

$3(27 \%)$

$8(73 \%)$

$6(55 \%)$

$5(45 \%)$ phology. ${ }^{24-26}$ First, Schmidt et $a l^{16}$ identified a pattern of dysplasia, referred to as type 2 pattern dysplasia, arising in Barrett esophagus adjacent to invasive esophageal adenocarcinoma in 4 of 18 $(22 \%)$ patients. Recently, Rucker-Schmidt et $a l^{29}$ reported non adenomatous dysplasia in $6.7 \%$ 

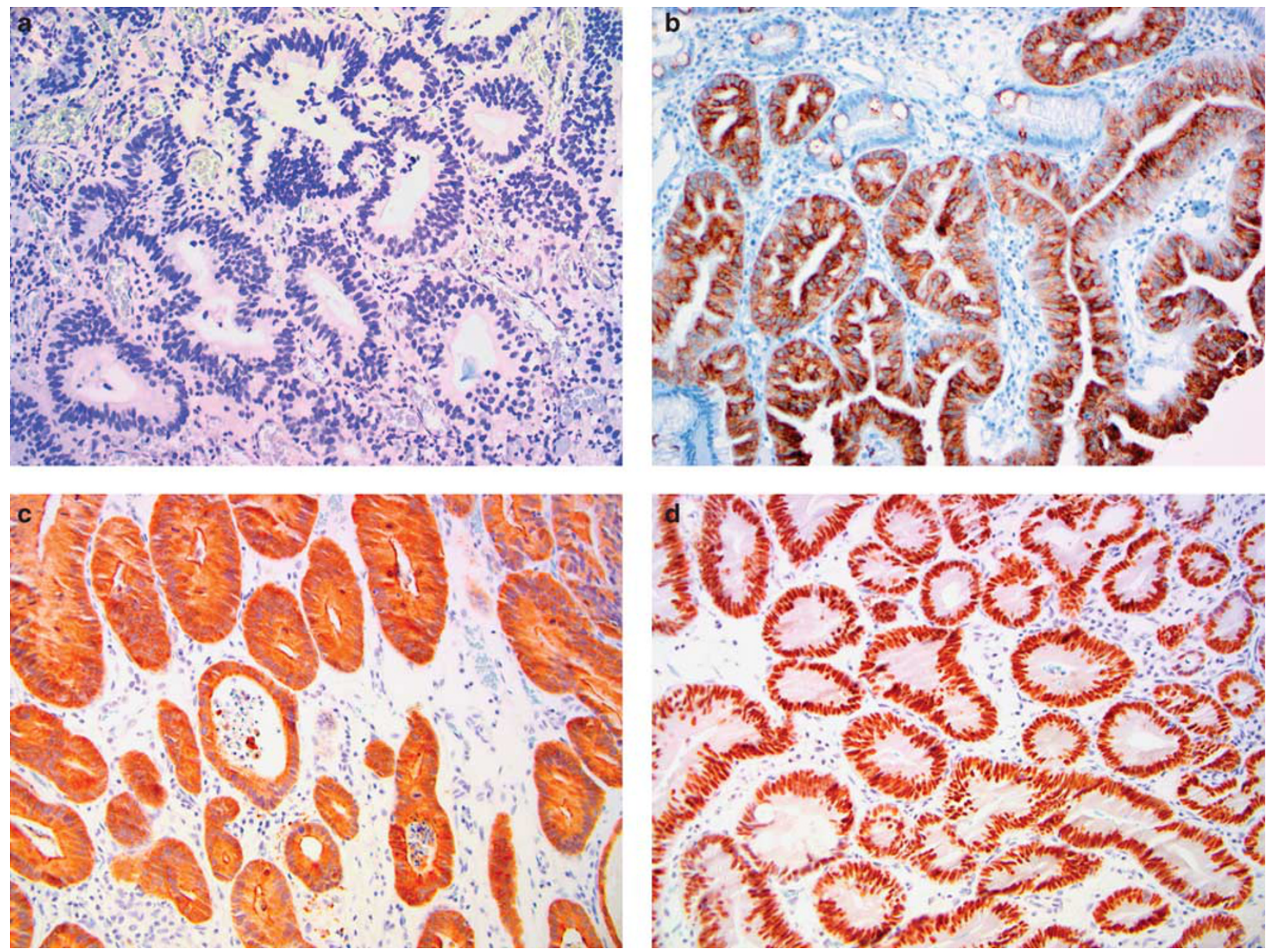

Figure 4 Adenomatous-type dysplasia. (a) Tumor cells are negative for MUC5AC. (b) Positive for MUC2. (c) Positive for villin. (d) Positive for CDX2.

of a cohort of 270 Barrett esophagus patients. Furthermore, gastric phenotype and gastric mucin expression has recently been reported in a case of polypoid Barrett esophagus dysplasia. ${ }^{41}$ Finally, there also exists one report of a lesion with features of pyloric gland adenoma arising in a Barrett esophagus background. ${ }^{42}$ Globally, these reports indicate a more heterogeneous morphotype of dysplasia in Barrett esophagus than is generally recognized.

As our study was based on esophagogastrectomy specimens performed for the treatment of invasive adenocarcinoma or extensive high grade dysplasia, we were able to observe Barrett esophagus dysplasia that was advanced to its full neoplastic potential. We have established that a foveolar phenotype of Barrett esophagus dysplasia not only exists, but is in fact common and clinically significant. Our data suggest that indeed Barrett esophagus dysplasia takes two main forms-gastric foveolar type and adenomatous type. The clinicopathological overlap between adenomatous and hybrid-type patterns were such that a separate hybrid category could not be sustained. Essentially, the demonstration of intestinal differentiation by either morphology or immunoreactivity for intestinal markers places a lesion in the adenomatous dysplasia group.

Interestingly, high grade dysplasia was more commonly identified in the adenomatous and hybrid-type dysplasias (91 and 100\%, respectively) than in the foveolar type (58\%). This is opposite to the publication by Rucker-Schmidt et $a l^{29}$ who reported significantly higher rate of DNA content abnormalities in non-adenomatous dysplasia compared with the rest of the cohort. It is possible that variation in diagnostic criteria explain the difference. However, the current results are also in opposition to the situation reported in gastric epithelial dysplasia where foveolar-type dysplasia was significantly more likely to show high-grade dysplasia than adenomatous type dysplasia. ${ }^{28}$ It is possible that upon developing high-grade dysplasia, there is a rapid progression to invasive disease in foveolar dysplasia. Providing some evidence for this proposition was the frequent finding of apparent progression from low-grade to high-grade dysplasia to invasive adenocarcinoma often within a single high power field in foveolar dysplasia cases. 
The demonstration of foveolar dysplasia raises the inevitable question of its origin. A logical conclusion is that gastric metaplastic epithelium observed in Barrett esophagus can undergo neoplastic transformation. Another possibility is that in Barrett esophagus neoplasia originates from a stem cell that maintains the ability for divergent differentiation. Increasing support for a stem cell origin of the metaplastic epithelial types in Barrett esophagus is emerging, ${ }^{43,44}$ and the role of a stem cell in neoplastic progression has also been proposed. ${ }^{45}$ In either case, our data suggest that a goblet cell rich non-neoplastic Barrett esophagus background is more strongly associated with adenomatous type dysplasia.

In this study, $21 \%$ of esophagogastrectomy cases with dysplasia did not have associated intestinal metaplasia (goblet cells) in non-neoplastic metaplastic columnar mucosa. Incomplete sampling of the lesion could be responsible, however, we failed to show intestinal metaplasia in $14 \%$ of cases where the entire tumor (with associated Barrett esophagus) and gastroesophageal junction was embedded. In the latter situation, the extent of non neoplastic columnar epithelium was small $(2-6 \mathrm{~mm})$ and goblet cells may have been replaced by dysplasia or invasive tumor. Nonetheless, we cannot exclude the possibility that intestinal metaplasia may not be a prerequisite to all cases of dysplasia and adenocarcinoma arising in Barrett esophagus.

Furthermore, the statistically significant association in our study of the absence of intestinal metaplasia in foveolar type dysplasia cases raises the possibility of a non-intestinal neoplastic pathway. Two recent studies have suggested the same possibility. ${ }^{10,46}$ In a cohort of 712 British patients with endoscopic evidence Barrett esophagus, 44.9\% $(n=309)$ had no microscopic evidence of intestinal metaplasia. Furthermore, 11 patients (3.6\%) developed adenocarcinoma, a number not significantly different from the 28 out of 379 patients with intestinal metaplasia. ${ }^{46}$ Furthermore, a study of endoscopic mucosal resection specimens in 113 patients with minute BE adenocarcinoma (mean size of $6.9 \mathrm{~mm}$ ) did not find evidence of intestinal metaplasia in glandular mucosa on either side of the invasive carcinoma in $70 \% .{ }^{10}$

This has obvious implications for the diagnosis and follow up of $\mathrm{BE}$, in which the recognition of intestinal metaplasia is sine qua non for a diagnosis of BE. However, it is worth noting that, recently, the British Society of Gastroenterology has argued that the $\mathrm{BE}$ diagnosis should not rely solely on the finding of goblet cells. ${ }^{47}$

As our study was performed on lesions advanced in their neoplastic progression, it is difficult to draw any conclusion from our data as to the frequency and biological potential of foveolar type dysplasia in routine screening biopsies. Although unproven, it is possible that foveolar differentiation occurs as a late event in neoplastic progression. This could account for the infrequent reporting of this pattern in small biopsies. Alternatively, foveolar dysplasia may represent an aggressive pattern with more frequent progression to invasive disease, thus escaping distinction on biopsies but accounting for the high frequency in our study based on resection specimens. Interestingly, the study by Rucker-Schmidt et $a l^{29}$ reported a higher rate of DNA content abnormalities in non-adenomatous dysplasia compared with the rest of their biopsy cohort.

In summary, our study validates a morphological subclassification of Barrett esophagus dysplasia into adenomatous and gastric foveolar types. Although many clinical features are similar, adenomatous dysplasia is more likely to arise in a goblet cell rich background. Alternatively, our results suggest that a non-intestinal pathway to neoplastic development (that is, gastric metaplasia-foveolar dysplasia) could be involved in the development of a subset of adenocarcinoma. If confirmed, our findings could be the basis for challenging current surveillance protocol and emphasis on the presence of intestinal epithelium. Furthermore, pathologists should be made aware of the foveolar type pattern of dysplasia, a potentially more aggressive lesion, which can herald malignant transformation.

\section{Acknowledgements}

This study was supported by grants the Cancer Council Queensland and the National Health and Medical Research Council (NHMRC) of Australia (Program no. 199600). David C Whiteman is a Principal Research Fellow funded by the NHMRC. The funding bodies had no role in the design or conduct of the study; the collection, management, analysis, or interpretation of the data; or preparation, review or approval of the article. The Australian Cancer Study Chief Investigators are David C Whiteman MBBS, PhD, Penelope M Webb MA, D Phil, Adele C Green MBBS, PhD, Nicholas K Hayward $\mathrm{PhD}$, Peter G Parsons PhD, David M Purdie PhD.

\section{Disclosure/conflict of interest}

The authors declare no conflict of interest.

\section{References}

1 Vizcaino AP, Moreno V, Lambert R, et al. Time trends incidence of both major histologic types of esophageal carcinomas in selected countries, 1973-1995. Int J Cancer 2002;99:860-868.

2 Devesa SS, Blot WJ, Fraumeni Jr JF. Changing patterns in the incidence of esophageal and gastric carcinoma in the United States. Cancer 1998;83:2049-2053.

3 Botterweck AA, Schouten LJ, Volovics A, et al. Trends in incidence of adenocarcinoma of the oesophagus and 
gastric cardia in ten European countries. Int J Epidemiol 2000;4:645-654.

4 Lord RV, Law MG, Ward RL, et al. Rising incidence of oesophageal adenocarcinoma in men in Australia. J Gastroenterol Hepatol 1998;4:356-362.

5 Shaheen NJ. Advances in Barrett's esophagus and esophageal adenocarcinoma. Gastroenterology 2005; 128:1554-1566.

6 Paull A, Trier JS, Dalton MD, et al. The histologic spectrum of Barrett's esophagus. N Engl J Med 1976;295:476-480.

7 Skinner DB, Walther BC, Riddell RH, et al. Barrett's esophagus. Comparison of benign and malignant cases. Ann Surg 1983;198:554-565.

8 Hamilton SR, Smith RR. The relationship between columnar epithelial dysplasia and invasive adenocarcinoma arising in Barrett's esophagus. Am J Clin Pathol 1987;87:301-312.

9 Spechler SJ, Goyal RK. The columnar-lined esophagus, intestinal metaplasia, and Norman Barrett. Gastroenterology 1996;110:614-621.

10 Takubo K, Aida J, Naomoto Y, et al. Cardiac rather than intestinal-type background in endoscopic resection specimens of minute Barrett adenocarcinoma. Hum Pathol 2009;40:65-74.

11 Clark GW, Smyrk TC, Burdiles P, et al. Is Barrett's metaplasia the source of adenocarcinomas of the cardia? Arch Surg 1994;129:609-614.

12 Cameron AJ, Souto EO, Smyrk TC. Small adenocarcinomas of the esophagogastric junction: association with intestinal metaplasia and dysplasia. Am J Gastroenterol 2002;97:1375-1380.

13 Cameron AJ, Lomboy CT, Pera M, et al. Adenocarcinoma of the esophagogastric junction and Barrett's esophagus. Gastroenterology 1995;109:1541-1546.

14 Nunobe S, Nakanishi Y, Taniguchi $\mathrm{H}$, et al. Two distinct pathways of tumorigenesis of adenocarcinomas of the esophagogastric junction, related or unrelated to intestinal metaplasia. Pathol Int 2007;57: 315-321.

15 Chandrasoma P, Wickramasinghe $\mathrm{K}$, Ma Y, et al. Is intestinal metaplasia a necessary precursor lesion for adenocarcinomas of the distal esophagus, gastroesophageal junction and gastric cardia? Dis Esophagus 2007;20:36-41.

16 Schmidt HG, Riddell RH, Walther B, et al. Dysplasia in Barrett's Esophagus. J Cancer Red Clin Oncol 1985;110:145-152.

17 Riddell RH, Odze RD. Definition of Barrett's Esophagus: Time for a Rethink-Is Intestinal Metaplasia Dead? Am J Gastroenterol 2009;104:2588-2594.

18 Steininger H, Pfofe DA, Müller H, et al. Expression of CDX2 and MUC2 in Barrett's mucosa. Pathol Res Pract 2005;201:573-577.

19 Groisman GM, Amar M, Meir A. Expression of the intestinal marker Cdx2 in the columnar-lined esophagus with and without intestinal (Barrett's) metaplasia. Mod Pathol 2004;17:1282-1288.

20 Phillips RW, Frierson Jr HF, Moskaluk CA. Cdx2 as a marker of epithelial intestinal differentiation in the esophagus. Am J Surg Pathol 2003;27:1442-1447.

21 Shi XY, Bhagwandeen B, Leong AS. CDX2 and villin are useful markers of intestinal metaplasia in the diagnosis of Barrett esophagus. Am J Clin Pathol 2008;129:571-577.

22 Liu W, Hahn H, Odze RD, et al. Metaplastic esophageal columnar epithelium without goblet cells shows DNA content abnormalities similar to goblet cell-containing epithelium. Am J Gastroenterol 2009;104:816-824.

23 Hahn HP, Blount PL, Ayub $\mathrm{K}$, et al. Intestinal Differentiation in Metaplastic, Nongoblet Columnar Epithelium in the Esophagus. Am J Surg Pathol 2009;33:1006-1015.

24 Wang KK, Sampliner RE, Practice Parameters Committee of the American College of Gastroenterology. Updated guidelines 2008 for the diagnosis, surveillance and therapy of Barrett's esophagus. Am J Gastroenterol 2008;103:788-797.

25 Odze RD. Update on the diagnosis and treatment of Barrett esophagus and related neoplastic precursor lesions. Arch Pathol Lab Med 2008;132:1577-1585.

26 Yantiss RK, Odze RD. Neoplastic precursor lesions of the upper gastrointestinal tract. Diag Histopathol 2008;14:437-451.

27 Odze RD. Diagnosis and grading of dysplasia in Barrett's oesophagus. J Clin Pathol 2006;59:1029-1038.

28 Park do Y, Srivastava A, Kim GH, et al. Adenomatous and foveolar gastric dysplasia: distinct patterns of mucin expression and background intestinal metaplasia. Am J Surg Pathol 2008;32:524-533.

29 Rucker-Schmidt RL, Sanchez CA, Blount PL, et al. Nonadenomatous dysplasia in Barrett Esophagus: a clinical, pathologic, and DNA content flow cytometric study. Am J Surg Pathol 2009;33:886-893.

30 Yonezawa S, Nakamura A, Horinouchi M, et al. The expression of several types of mucin is related to the biological behavior of pancreatic neoplasms. J Hepatobiliary Pancreat Surg 2002;9:328-341.

31 Ban S, Naitoh Y, Mino-Kenudson M, et al. Intraductal papillary mucinous neoplasm (IPMN) of the pancreas: its histopathologic difference between 2 major types. Am J Surg Pathol 2006;30:1561-1569.

32 Katabi N, Klimstra DS. Intraductal papillary mucinous neoplasms of the pancreas: clinical and pathological features and diagnostic approach. J Clin Pathol 2008; 61:1303-1313.

33 Whiteman DC, Sadeghi S, Pandeya N, et al. Combined effects of obesity, acid reflux and smoking on the risk of adenocarcinomas of the oesophagus. Gut 2008;57:173-180.

34 Hamilton SR, Aaltonen LA, (eds). World Health Organization Classification of Tumors. Pathology and Genetics of Tumors of the Digestive System. IARC Press: Lyon, 2000.

35 Montgomery E, Bronner MP, Goldblum JR, et al. Reproducibility of the diagnosis of dysplasia in Barrett esophagus: a reaffirmation. Hum Pathol 2001;32: 368-378.

36 Mahajan D, Bennett AE, Liu X, et al. Grading of gastric foveolar-type dysplasia in Barrett's esophagus. Mod Pathol 2010;23:1-11.

37 Takubo K, Aida J, Sawabe M, et al. The normal anatomy around the oesophagogastric junction: a histopathologic view and its correlation with endoscopy. Best Pract Res Clin Gastroenterol 2008;22: 569-583.

38 Takubo K, Sasajima K, Yamashita K, et al. Double muscularis mucosae in Barrett's esophagus. Hum Pathol 1991;22:1158-1161.

39 Lewis JT, Wang KK, Abraham SC. Muscularis mucosae duplication and the musculo-fibrous anomaly in endoscopic mucosal resections for Barrett esophagus: implications for staging of adenocarcinoma. Am J Surg Pathol 2008;32:566-571. 
40 DeNardi FG, Riddell RH. The normal esophagus. Am J Surg Pathol 1991;15:296-309.

41 Asthana N, Mandich D, Ligato S. Esophageal polypoid dysplasia of gastric foveolar phenotype with focal intramucosal carcinoma associated with Barrett's esophagus. Am J Surg Pathol 2008;32:1581-1585.

42 Kushima R, Vieth M, Mukaisho K, et al. Pyloric gland adenoma arising in Barrett's esophagus with mucin immunohistochemical and molecular cytogenetic evaluation. Virchows Arch 2005;446:537-541.

43 Leedham SJ, Preston SL, McDonald SA, et al. Individual crypt genetic heterogeneity and the origin of metaplastic glandular epithelium in human Barrett's oesophagus. Gut 2008;57:1041-1048.
44 Sarosi G, Brown G, Jaiswal K, et al. Bone marrow progenitor cells contribute to esophageal regeneration and metaplasia in a rat model of Barrett's esophagus. Dis Esophagus 2008;21:43-50.

45 Zhang HY, Spechler SJ, Souza RF. Esophageal adenocarcinoma arising in Barrett esophagus. Cancer Lett 2009;275:170-177.

46 Kelty CJ, Gough MD, Van Wyk Q, et al. Barrett's oesophagus: intestinal metaplasia is not essential for cancer risk. Scand J Gastroenterol 2007;42: 1271-1274.

47 Playford RJ. New British Society of Gastroenterology (BSG) guidelines for the diagnosis and management of Barrett's oesophagus. Gut 2006;55:442. 